\title{
Effects of Psychotropic Drugs on Seizure Threshold during Electroconvulsive Therapy
}

\author{
Su-Hyuk Chi', Hyun-Ghang Jeong ${ }^{1,2} \bowtie$, Suji Lee ${ }^{3}$, So-Young Oh${ }^{4}$, and Seung-Hyun Kim ${ }^{1}$ \\ ${ }^{1}$ Department of Psychiatry, Korea University Guro Hospital, Korea University College of Medicine, Seoul, Republic of Korea \\ ${ }^{2}$ Korea University Research Institute of Mental Health, Seoul, Republic of Korea \\ ${ }^{3}$ Department of Biomedical Science, Korea University Graduate School, Seoul, Republic of Korea \\ ${ }^{4}$ Seoul Metropolitan Enpyeong Hospital, Seoul, Republic of Korea
}

Objectives To analyze the relationship between seizure threshold (ST) and psychotropic drugs in patients treated with ECT.

Methods We examined clinical data from 43 patients. ST was titrated at each treatment session. We examined associations between ST and psychotropic drugs using multivariate correlation analyses. Data are presented as initial ST, the difference in ST between the first and 10th sessions $\left(\Delta \mathrm{ST}_{10 \mathrm{th}}\right)$, and the mean difference in $\mathrm{ST}$ between the first and last sessions (mean $\Delta \mathrm{ST}_{\text {last }}$ ).

Results Multivariate regression analyses showed associations between initial ST and the total chlorpromazine-equivalent dose of antipsychotics $(\beta=0.363, \mathrm{p}<0.05)$. The total fluoxetine-equivalent dose of antidepressants was associated with $\Delta \mathrm{ST}_{10 \text { th }}(\beta=0.486, \mathrm{p}<0.01)$ and mean $\Delta \mathrm{ST}_{\text {last }}(\beta=0.472, \mathrm{p}<0.01)$.

Conclusion Our study elucidated possible effects of psychotropic drugs on ST shifts. Larger doses of antipsychotics were associated with higher initial ST, whereas higher doses of antidepressants were associated with stronger shifts in ST.

Psychiatry Investig 2017;14(5):647-655

Key Words Electroconvulsive therapy, Seizure threshold, Antipsychotics, Antidepressants.

\section{INTRODUCTION}

Various kinds of brain stimulation therapies are widely used to treat discrete psychiatric disorders. Deep brain stimulation, repetitive transcranial magnetic stimulation, and vagus nerve stimulation are just a few of the tools used to stimulate the brain's neurons in the hope of achieving beneficial effects for patients with psychiatric diseases. Electroconvulsive therapy (ECT) is one of the oldest and most popular ways to achieve therapeutic effects by stimulating the brain with the help of electrical currents. ${ }^{1,2}$ ECT had a poor initial reputation due to the use of electricity directly on the patient's head. But treatment procedures have evolved significantly and proven to be safe

Received: August 26, 2016 Revised: September 27, 2016

Accepted: October 16, 2016 Available online: June 16, 2017

$\triangle$ Correspondence: Hyun-Ghang Jeong, MD, PhD

Department of Psychiatry, Korea University Guro Hospital, Korea University College of Medicine, 148 Gurodong-ro, Guro-gu, Seoul 08308, Republic of Korea

Tel: +82-2-2626-3164, Fax: +82-2-852-1937, E-mail: parapraxis@naver.com

(a) This is an Open Access article distributed under the terms of the Creative Commons Attribution Non-Commercial License (http://creativecommons.org/licenses/bync/4.0) which permits unrestricted non-commercial use, distribution, and reproduction in any medium, provided the original work is properly cited. and effective. The introduction of anesthesia and muscle relaxants greatly improved the subjective treatment experience, in addition to decreasing serious side effects such as spine fractures or dental issues. The therapeutic effect of ECT emerges from the induction of a generalized seizure. ${ }^{3}$ The minimal amount of electrical energy needed to induce seizures is known as the seizure threshold (ST). It is commonly believed that treatment efficacy is related to stimulus dose relative to ST, but higher stimuli usually also increase unwanted side effects. ${ }^{3-6}$ Many treatment protocols, therefore, advise the use of justabove-threshold energy levels and provide guidance to find those numbers. ${ }^{7,8}$ Clinicians can use different algorithms to estimate initial ST, though some studies still emphasize the efficacy of empirical titration or fixed high initial dose methods. ${ }^{7,9}$

ST varies greatly by individual and can be affected by many factors. ${ }^{1}$ Previous studies agree that male sex, older age, higher body mass index (BMI), and bilateral electrode placement are associated with higher ST. ${ }^{2,3}, 10$ The contribution of benzodiazepines and anticonvulsant drugs to ST was partially confirmed by a Japanese study that found that prescriptions of benzodiazepines correlated with higher ST. ${ }^{11}$ Many efforts were made to counteract such increases in ST. The electrical 
waveform was changed from a sine wave to a brief pulse, further evolving to an ultra-brief pulse. ${ }^{4}$ Hyperventilation, adjustment of electrodes, and even proconvulsants were also considered, but not all trials were successful. ${ }^{12,13}$ Despite such efforts, ways to predict ST remain understudied. Among the few studies that do exist, an even smaller number focus on factors that affect the shift of ST during the course of ECT. One study in Bangkok showed that the magnitude of ST shifts associates positively with the number of sessions and negatively to initial ST, change in seizure duration, and response status. ${ }^{14}$ Other studies pointed out that younger age and the use of psychotropic drugs may be associated with lower seizure thresholds, but none examined the effects of drugs on the shift of ST during ECT, even though most patients routinely take concurrent psychotropic medication while undergoing treatment. ${ }^{15-17}$ Therefore, in this study, we focus on the effects of psychotropic drugs, both antipsychotics and antidepressants, on the ST shift in patients receiving ECT.

\section{METHODS}

\section{Participants}

We performed a retrospective study to investigate the effects of psychotropic drugs on ST among patients who received ECT at Korea University Guro Hospital (KUGH) between February 2009 and June 2015. Patients with a history of seizure disorders or other medical emergent conditions were excluded. A total of fifty-eight subjects received ECT during the study period. Patients were excluded if treatment was aborted due to side effects or any other reasons before the 10th session $(n=12)$ because we intended to investigate the ST shift during the course of consecutive ECT sessions. We included 43 subjects in the final data analysis. Among them, 5 had hypertension, 7 had diabetes, and 3 patients had subclinical hypothyroidism as medical comorbidities. Patients' psychiatric disorders were diagnosed according to the Diagnostic and Statistical Manual of Mental Disorders (DSM-IV-R) by at least two experienced psychiatrists in the usual clinical settings at KUGH. ECT was administrated with concurrent antipsychotics and antidepressants. Benzodiazepine, mood stabilizers with anticonvulsant effects such as lithium and valproic acid, and zdrugs such as zolpidem were tapered out before initiating ECT and not used until all treatment sessions ended. We documented ECT variables (including the time interval between the last and current titration sessions) and concomitant medication using medical records. The study protocol was approved by the Institutional Review Board of KUGH, and we obtained written informed consent from all participants for use of their clinical data. Consent was taken from guardians if the participant was thought to be unable to make clear decisions himself.

\section{ECT procedures}

All patients were admitted to KUGH at least one week before starting ECT procedures. We used a MECTA SpECTrum 5000Q apparatus for seizure induction. Patients were hyperventilated with $100 \%$ oxygen for 10 seconds and anaesthetized using propofol $(1-2 \mathrm{mg} / \mathrm{kg})$. We used succinylcholine $(0.5 \mathrm{mg} /$ $\mathrm{kg}$ ) to induce muscle relaxation and conducted clinical monitoring, including electrocardiographic and electroencephalographic (EEG), throughout the whole procedure. Propofol and succinylcholine doses were kept consistent throughout all treatment sessions. We placed ECT electrodes at the bilateral temporal areas and applied the electrical stimulus as soon as the patient reached the deepest stage of anesthesia. Initial stimulus strength varied between 10J and 15J, converted from the recommended initial $50 \mathrm{mC}$ at $220 \mathrm{ohm}$ patient impedance. ${ }^{8}$ Seizure induction was considered successful if the seizure lasted for more than 25 seconds. Stimulus strength was maintained after a successful session. After an unsuccessful trial, we increased stimulus strength stepwise by $2 \mathrm{~J}$ to $5 \mathrm{~J}$ per trial. We performed a maximum of 4 stimulations at each treatment session, with an interval of at least 30s between stimuli. Each patient underwent 10 to 20 sessions, based on the psychiatrist's clinical decision. We considered the stimulus strength of the first successfully induced seizure to be the minimal ST. We used the cuff method to determine seizure duration, along with mastoid EEG channels.

\section{Statistical analysis}

We present the following data: initial ST is the amount of electrical energy used to induce a successful seizure at the first session; $\Delta \mathrm{ST}_{10 \mathrm{th}}$ is the difference in ST between the first and 10th sessions; mean $\Delta \mathrm{ST}_{\text {last }}$ is the mean difference in $\mathrm{ST}$ between the first and last sessions. We used stepwise multivariate regression analyses to find associations between those data and the doses of psychotropic medication, adjusting for age, sex, and BMI. We performed univariate regression analyses to find associations between laboratory test results and ST. We used covariance analyses to find differences in variables between clinical subgroups divided by types of prescribed medication, adjusting for age, sex, and BMI. All statistical analyses were performed using the SPSS 19 statistical package (IBM Corp., Armonk, NY, USA).

\section{RESULTS}

\section{Demographics and clinical variables}

Of the 43 patients included in the study, 20 were male, and the other 23 were female. The mean age of all participants was 41.44 years $(\mathrm{SD}=15.89)$, with a total range from 15 to 71 years old. 29 patients were diagnosed with schizophrenia, 4 with 
schizoaffective disorder, 9 with major depressive disorder, and 1 with bipolar disorder, according to DSM-IV-R criteria. All medication was prescribed by psychiatrists. Use of benzodiazepines, z-drugs, and anticonvulsants was avoided during ECT administration. Patients were taking the following antipsychotics and antidepressants: clozapine $(n=6)$, amisulpride $(n=9)$, aripiprazole $(n=5)$, olanzapine $(n=18)$, risperidone $(n=1)$, quetiapine $(n=20)$, haloperidol $(n=1)$, paliperidone $(n=5)$, chlorpromazine $(n=1)$, blonanserin $(n=1)$, escitalopram $(n=7)$, sertraline $(n=1)$, mirtazapine $(n=2)$, duloxetine $(n=1)$, venlafaxine $(n=3)$, amitriptyline $(n=1)$, trazodone $(n=1)$, bupropion $(\mathrm{n}=1)$. Participants took an average of $1.91(\mathrm{SD}=1.02$, range $0-5$ ) different psychotropic drugs during ECT. The mean number of types of antipsychotics and antidepressants used were $1.53(\mathrm{SD}=0.74$, range $0-3$ ) and $0.37(\mathrm{SD}=0.76$, range $0-4$ ), respectively. We converted the dose and types of antipsychotics and antidepressants into chlorpromazine (CPZ) and fluoxetine (FXT) equivalences, respectively. ${ }^{18-20}$ For detailed information on drug dose equivalences (Table 1). Patients received an average of 14.4 sessions of ECT ( $\mathrm{SD}=3.06$, range 10-20). Sociodemographic data are summarized in Table 2.

Table 1. Type and equivalent dose of antipsychotics and antidepressants

\begin{tabular}{lc}
\hline \multicolumn{1}{c}{ Drug } & Dose equivalence \\
\hline Antipsychotics & 125 \\
Amisulpride & 7.5 \\
Aripiprazole & 4 \\
Blonanserin & 100 \\
Chlorpromazine & 50 \\
Clozapine & 2 \\
Haloperidol & 25 \\
Olanzapine & 3 \\
Paliperidone & 75 \\
Quetiapine & 2 \\
Risperidone & \\
Antidepressants & 3.3 \\
Amitriptyline & 1.2 \\
Bupropion & 6.6 \\
Duloxetine & 20 \\
Escitalopram & 10 \\
Fluoxetine & 7.5 \\
Mirtazapine & 4 \\
Sertraline & 1 \\
Trazodone & 2.7 \\
Venlafaxine & \\
\hline
\end{tabular}

Data presented as chlorpromazine-equivalent dose for antipsychotics; fluoxetine-equivalent dose for antidepressants

\section{Effect of psychotropic drugs on ST}

Of the 43 patients, 40 used at least one antipsychotic drug, 12 used more than one antidepressant, and 3 did not take any psychotropic medication while undergoing ECT (Table 2). The total CPZ equivalent dose of antipsychotics $(B=0.363$, $\mathrm{p}<0.05)$ was positively associated with initial ST. The total FXT equivalent dose of antidepressants, on the other hand, was positively associated with $\Delta \mathrm{ST}_{10 \text { th }}(\mathrm{B}=0.486, \mathrm{p}<0.01)$ and mean $\Delta \mathrm{ST}_{\text {last }}(\mathrm{B}=0.472, \mathrm{p}<0.01)$ (Figure 1).

\section{Effect of combination therapy on ST}

We divided the subjects into four subgroups to further analyze the effects of drug combinations: 11 patients took only one antipsychotic medication, 6 patients took one antipsychotic in combination with antidepressants, 17 patients took multiple antipsychotics, and 6 patients took multiple antipsychotics in combination with antidepressants (Table 2). We performed an ANCOVA for initial ST, $\Delta \mathrm{ST}_{10 \text { th }}$, and mean $\Delta \mathrm{ST}_{\text {last }}$ and adjusted the results for age, sex, and BMI. The initial ST was

Table 2. Sociodemographic and clinical characteristics of the study sample

\begin{tabular}{|c|c|}
\hline \multicolumn{2}{|l|}{ Clinical variables } \\
\hline \multicolumn{2}{|l|}{ Patient characteristics, N (\%) } \\
\hline Male & $20(46.5)$ \\
\hline Female & $23(53.5)$ \\
\hline Mean age, in years & 41.44 \\
\hline \multicolumn{2}{|l|}{ Diagnosis, N (\%) } \\
\hline Schizophrenia & $29(67.4)$ \\
\hline Schizoaffective disorder & $4(9.3)$ \\
\hline Major depressive disorder & $9(20.9)$ \\
\hline Bipolar disorder & $1(2.3)$ \\
\hline \multicolumn{2}{|l|}{ Drug use, $\mathrm{N}(\%)$} \\
\hline No drug use & $3(7.0)$ \\
\hline Antipsychotics & $40(93.0)$ \\
\hline Antidepressants & $12(27.9)$ \\
\hline \multicolumn{2}{|l|}{ Number of used drugs, mean \pm SD } \\
\hline Total psychotropic drugs & $1.91 \pm 1.02$ \\
\hline Types of antipsychotics & $1.53 \pm 0.74$ \\
\hline Types of antidepressants & $0.37 \pm 0.76$ \\
\hline \multicolumn{2}{|l|}{ Drug combination, $\mathrm{N}(\%)$} \\
\hline One antipsychotic & $11(25.6)$ \\
\hline One antipsychotic+any antidepressants & $6(14.0)$ \\
\hline Antipsychotic combination & $17(39.5)$ \\
\hline Antipsychotic combination+any antidepressants & $6(14.0)$ \\
\hline \multicolumn{2}{|l|}{$\mathrm{ECT}$, mean $\pm \mathrm{SD}$} \\
\hline Sessions & $14.40 \pm 3.06$ \\
\hline
\end{tabular}



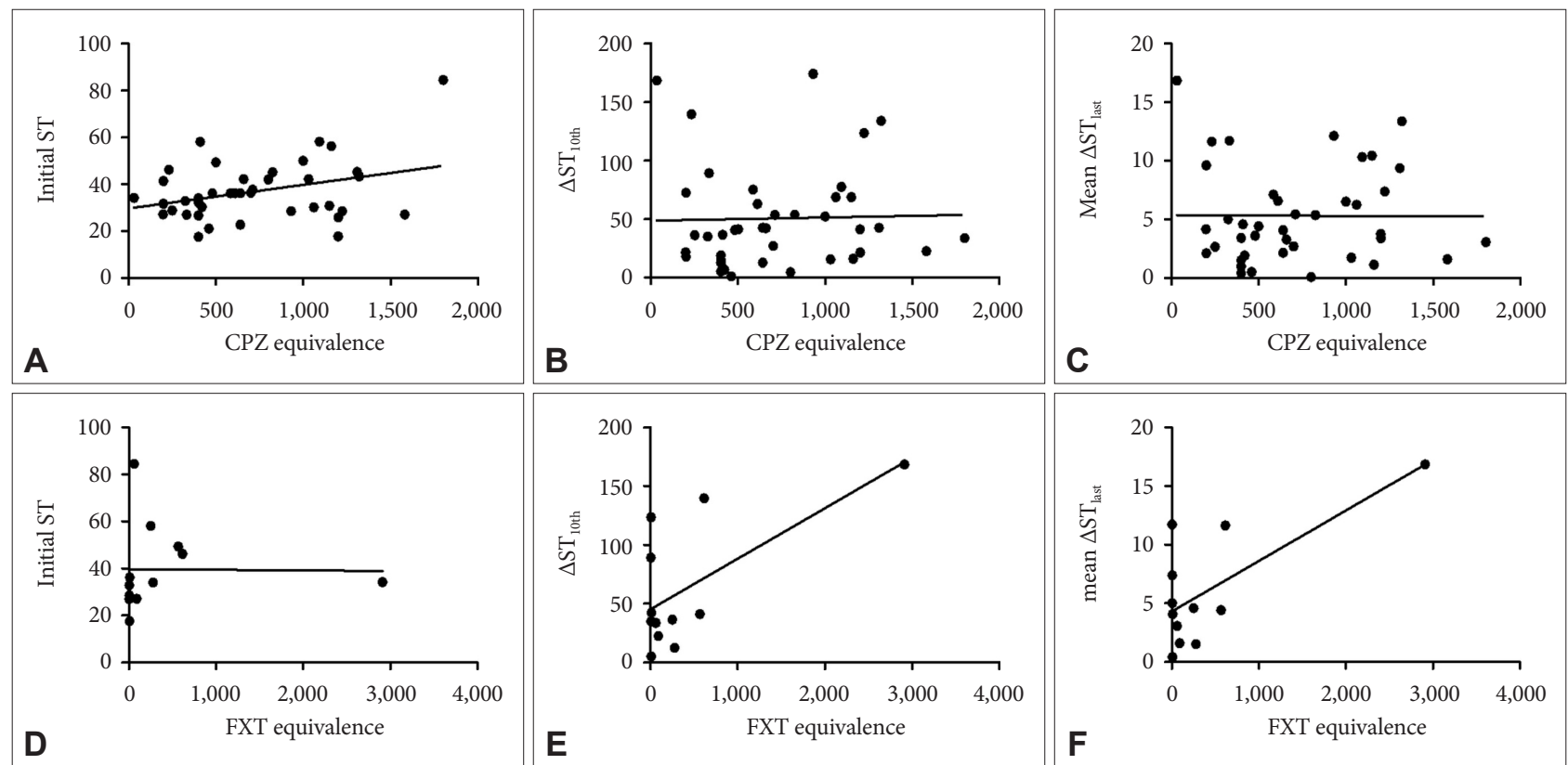

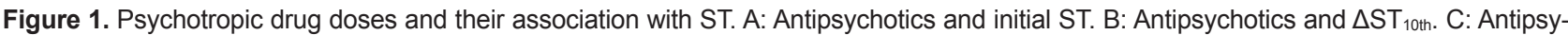
chotics and mean $\Delta S T_{\text {last. }} \mathrm{D}$ : Antidepressants and initial ST. E: Antidepressants and $\Delta \mathrm{ST}_{10 \mathrm{th} .} \mathrm{F}$ : Antidepressants and mean $\Delta S T_{\text {last. }}$ Variables: $\Delta \mathrm{ST}_{10 \mathrm{th}}$, difference in seizure thresholds between first and 10th sessions, mean $\Delta \mathrm{ST}_{\text {last: }}$ mean difference in seizure thresholds between first and last sessions. ST: seizure threshold in jaules, CPZ: chlorpromazine, FXT: fluoxetine.

Table 3. ANCOVA results for associations between drug combinations and seizure threshold

\begin{tabular}{lcccccc}
\hline & One AP & One AP+any AD & AP combination & AP combination+any AD & F & p-value \\
\hline Initial ST & $32.89 \pm 6.16$ & $34.05 \pm 10.12$ & $37.73 \pm 11.61$ & $45.23 \pm 23.02$ & 1.199 & 0.328 \\
$\Delta \mathrm{ST}_{10 \text { th }}$ & $31.14 \pm 23.50$ & $50.85 \pm 59.72$ & $54.86 \pm 44.28$ & $74.22 \pm 50.36$ & 0.630 & 0.645 \\
Mean $\Delta \mathrm{ST}_{\text {last }}$ & $3.52 \pm 2.72$ & $5.39 \pm 5.90$ & $5.98 \pm 3.96$ & $6.67 \pm 4.33$ & 0.491 & 0.742 \\
\hline
\end{tabular}

Data presented as mean \pm standard deviation. Adjusted for age, sex, and BMI. Variables: $\Delta \mathrm{ST}_{10 \mathrm{th}}$, difference in seizure thresholds between first and 10th sessions, mean $\Delta \mathrm{ST}_{\text {last: }}$ mean difference in seizure thresholds between first and last sessions. ANCOVA: analysis of covariance, AP: antipsychotic, AD: antidepressant, ST: seizure threshold in jaules, BMI: body mass index

highest in the group using multiple antipsychotics in combination with antidepressants $(45.23 \pm 23.02)$ and lowest in the group using only one antipsychotic $(32.89 \pm 6.16) . \Delta \mathrm{ST}_{10 \text { th }}$ and mean $\Delta \mathrm{ST}_{\text {last }}$ showed similar results $(31.14 \pm 23.50$ vs. $74.22 \pm$ 50.36 , and $3.52 \pm 2.72$ vs. $6.67 \pm 4.33$, respectively). Those results suggest that use of multiple drugs is associated with higher initial ST and greater increases of ST during ECT (Table 3). However, those differences were not statistically significant.

\section{Laboratory test results and ST}

Lab results were significant. Initial ST was positively associated with serum triglyceride levels $(\mathrm{B}=0.390, \mathrm{p}<0.05) . \Delta \mathrm{ST}_{10 \text { th }}$ showed positive associations with serum low density lipoprotein $(\mathrm{LDL})(\mathrm{B}=0.412, \mathrm{p}<0.05)$, and serum triiodothyronine levels showed associations with mean $\Delta \mathrm{ST}_{\text {last }}(\mathrm{B}=0.326, \mathrm{p}<0.05)$. See Table 4 for a summary of all regression analyses.

\section{DISCUSSION}

Optimal electrical stimulus is critical for inducing therapeu- tic seizures in ECT. As previous studies suggest, energy levels exceeding ST are necessary to achieve proper therapeutic effects. ${ }^{3-8}$ Our research focused on the effects of psychotropic drugs on initial ST and the shift of ST during ECT. We found that both antipsychotics and antidepressants affect the increase of ST, and their associations seem to have dose-dependent patterns. Higher doses of antipsychotics are associated with higher initial ST, and higher doses of antidepressants are associated with larger shifts of ST during the course of treatment.

It was traditionally thought that dopamine agonists could provoke and modulate seizures, increasing the number and severity of attacks. ${ }^{21}$ One Japanese study investigated the effects of antipsychotic drugs on epilepsy patients and found that the group taking antipsychotic agents tended to have fewer seizure incidents than controls. ${ }^{22}$ Dopamine antagonists, however, showed inconsistent effects in provoking seizures. Some studies suggested that antipsychotics have dose-dependent proconvulsive characteristics. ${ }^{23}$ Several articles particularly pointed to the epileptogenic properties of clozapine. ${ }^{24-26}$ On the other hand, consistent with our results, other studies reported 
Table 4. Multiple regression analysis of factors affecting ST

\begin{tabular}{|c|c|c|c|c|c|c|c|c|c|}
\hline \multirow{2}{*}{ Variable } & \multicolumn{3}{|c|}{ Initial ST } & \multicolumn{3}{|c|}{$\Delta \mathrm{ST}_{10 \text { th }}$} & \multicolumn{3}{|c|}{ Mean $\Delta \mathrm{ST}_{\text {last }}$} \\
\hline & B & SE B & $\beta$ & B & SE B & $\beta$ & B & SE B & $\beta$ \\
\hline \multicolumn{10}{|l|}{ Demographics } \\
\hline Age & 0.165 & 0.141 & 0.208 & 0.311 & 0.467 & 0.116 & 0.038 & 0.044 & 0.150 \\
\hline Sex & -3.792 & 4.387 & -0.153 & 3.739 & 14.503 & 0.044 & -0.221 & 1.371 & -0.028 \\
\hline BMI & 0.616 & 0.438 & 0.215 & 1.9030 & 1.447 & 0.194 & 0.178 & 0.137 & 0.195 \\
\hline \multicolumn{10}{|c|}{ Psychotropic drug dose } \\
\hline Antipsychotics & 0.010 & 0.005 & $0.363^{*}$ & 0.016 & 0.015 & 0.168 & 0.001 & 0.001 & 0.104 \\
\hline Antidepressants & 0.004 & 0.004 & 0.145 & 0.045 & 0.014 & $0.486^{\dagger}$ & 0.004 & 0.001 & $0.472^{\dagger}$ \\
\hline \multicolumn{10}{|l|}{ Lab results } \\
\hline Triglyceride & 0.057 & 0.023 & $0.538^{*}$ & -0.041 & 0.094 & -0.086 & -0.005 & 0.009 & -0.112 \\
\hline LDL & -0.115 & 0.062 & -0.396 & 0.635 & 0.257 & $0.492^{*}$ & 0.055 & 0.023 & $0.473^{*}$ \\
\hline T3 & 0.001 & 0.001 & 0.105 & 0.011 & 0.005 & $0.369^{*}$ & 0.001 & 0.000 & $0.390^{*}$ \\
\hline $\mathrm{R}^{2}$ & & 0.254 & & & 0.298 & & & 0.533 & \\
\hline $\mathrm{F}$ & & $2.518^{*}$ & & & $3.134^{*}$ & & & $2.944^{*}$ & \\
\hline
\end{tabular}

Variables: $\Delta \mathrm{ST}_{10 \text { th }}$, difference in seizure thresholds between first and 10th sessions, mean $\Delta \mathrm{ST}_{\text {last: }}$ mean difference in seizure thresholds between first and last sessions. ${ }^{*} \mathrm{p}<0.05,{ }^{\dagger} \mathrm{p}<0.01$. ST: seizure threshold in jaules, BMI: body mass index, LDL: low density lipoprotein, B: regression coefficient, SE: standard error, $\beta$ : standardized regression coefficient, T3: triiodothyronine

possible anticonvulsant effects for antipsychotic medication, especially second-generation drugs. ${ }^{15,17}$ A recent study found antiepileptic effects of aripiprazole during pharmacologically or electrically induced seizures in mice. ${ }^{27}$

The exact mechanisms by which antipsychotics affect ST remain unknown, but some plausible explanations are possible.

First, dopamine itself is known for its possible seizure-evoking properties. Dopamine, mainly through $\mathrm{D} 1$ receptors in the midbrain, has been shown to have proconvulsant effects. ${ }^{28}$ Animal studies confirmed that injection of D1 agonists can stimulate convulsions, just as cholinergic agonists do. ${ }^{29-31}$ The proconvulsive effects of dopamine agonists have also been shown to increase the severity of electrically induced seizures. ${ }^{32}$ Antipsychotic drugs might counter such actions through their dopamine antagonistic properties, which might increase ST.

Second, antipsychotics might have anticonvulsant effects via regulation of gamma-aminobutyric acid (GABA) transmission. GABA is already known to play an important role in elevating $\mathrm{ST}$, as shown by medications such as barbiturates or benzodiazepines. ${ }^{33,34}$ ECT itself leads to higher ST and increased GABA levels as sessions progress, adding additional weight to the link between GABA and anticonvulsant effects. ${ }^{35}$ Antipsychotics also induce an increase in intracerebral GABA concentrations. A study on rats showed that the administration of antipsychotic drugs led to a decrease in the density of GABA receptors, thereby indicating increased activity in the GABAergic system. ${ }^{36}$ How antipsychotics affect GABA is not yet clear, but animal studies suggest that dopamine antagonists, the main mechanism for most modern antipsychotics, seem to decrease the inhibitory effects of GABA antagonists, thereby leading to increased GABA activity. ${ }^{37}$ Primate studies have also revealed that GABAergic neurons express $\mathrm{D} 4$ receptors in various brain regions, including the cortex, hippocampus, basal ganglia, and substantia nigra, contributing to the idea that dopamine plays a role in GABAergic modulation. ${ }^{38}$ More recent in vitro studies suggest that dopamine has a biphasic effect on GABA: D2 agonists induce a rapid but short decrease in excitability, whereas D1 agonists lead to a slower but longer increase. ${ }^{39}$ This finding coincides with previous animal studies that used D1 receptor antagonist on rat brains to observe the consequent decrease of GABA release from striatal terminals. ${ }^{40,41}$ In vitro experiments supported the idea of D1-mediated excitatory influence and D2-mediated inhibitory action on GABA, but they also suggested a third excitatory pathway that does not depend on calcium channels, unlike the two previously mentioned pathways. ${ }^{42}$ Those results imply that antipsychotics could have antiepileptic effects through D2 antagonistic properties.

Third, the choice of antipsychotic medication might have affected outcomes directly. Previous reviews suggest that chlorpromazine and clozapine have higher risks for inducing seizures, whereas newer drugs such as risperidone, quetiapine, and olanzapine have relatively low risks. ${ }^{43,44} \mathrm{~A}$ study examining the EEG recordings of psychiatric patients also supports those results, stating that EEG abnormality risks vary among antipsychotic agents from clozapine at $47.1 \%$ to quetiapine at $0.0 \% .{ }^{45}$ Most patients in our study took second-generation antipsychotics. Almost all patients had quetiapine or olanzapine 
prescribed as their primary medication. Amisulpride, clozapine, risperidone, and other drugs were used in much lower numbers. No patient took chlorpromazine during the study. This preference for low-risk drugs might have affected our study in several ways, although the exact reason for the difference in seizure-inducing risk remain to be unveiled. The discrepancy between first- and second-generation medications might result from the different receptors that the drugs target. Modern drugs are mostly serotonin-dopamine antagonists, differentiating from classical agents through their occupancy of 5-HT receptors. ${ }^{46}$ This action gives second-generation drugs their anti-depressive properties and might also contribute to anticonvulsive effects through GABAergic modulation.

Another major finding of our study is the effect of antidepressants on ST during ECT. We discovered that antidepressants alter the shift of ST during the course of ECT sessions, resulting in larger and more drastic ST rises. Previous reports on the topic were controversial to some extent, showing mixed results. Antidepressants were traditionally thought to have the rare consequence of increased seizure risks. ${ }^{47}$ Previous reports revealed that risks for developing seizures in patients taking newer antidepressants is as low $(0.0-0.4 \%)$ as in the general population $(0.07-0.09 \%){ }^{48}$ More recent animal studies, however, emphasized the possible antiepileptic effects of antidepressants: Rats under long-term exposure to antipsychotics and antidepressants were observed for seizure development, and both fluoxetine and duloxetine exhibited anticonvulsant effects. ${ }^{49}$

Although the exact mechanisms are unknown, there are possible explanations for the effects of antidepressants on ST. GABAergic regulation caused by changes in serotonin levels might be the first plausible reason. SSRIs, among other classes of antidepressants, were reported to upregulate GABA receptors in animal models and clinical studies. ${ }^{50,51}$ Other studies also found that serotonin stimulates GABAergic interneurons directly. 52,53 -HT2 and 5-HT3 receptors are responsible for the release of GABA from GABAergic interneurons in the hippocampal region and dentate gyrus, respectively. ${ }^{54}$ Hence, increased serotonin concentrations lead to higher GABA levels, resulting in stronger anticonvulsant effects. Evidence for such effects is also seen in an animal study performed on epileptic rats and through studies on endogenous serotonin or acute administration of selective serotonin reuptake inhibitors in clinical settings. ${ }^{5-57}$ This hypothesis is also supported by the fact that anticonvulsants such as carbamazepine increase the release of serotonin in patients undergoing pharmacotherapy. ${ }^{17}$

Second, norepinephrine (NE), a neurotransmitter commonly modulated by antidepressants, also seems to contribute to seizure control. Previous studies indicated that NE target areas, such as the stria terminalis or hippocampus, show increased
GABAergic activity when exposed to chronic stress. ${ }^{58}$ An animal model promoted this idea by showing that the administration of reboxetine, a powerful NE reuptake inhibitor, increases GABAergic transmission in the limbic areas of rats. ${ }^{59}$ Similar conclusions were obtained in other animal studies: increased GABA concentrations occurred in the hypothalamic and hippocampal areas of rats following stimulation by NE. ${ }^{60,61}$ This GABA increase can result in higher ST, as explained above.

Third, evidence suggests that NE can affect seizures in other ways than by mediating GABA levels. An animal study reported that mice engineered to lack NE showed greater seizure susceptibility than control groups, also displaying higher severity and mortality rates from induced seizures. ${ }^{62}$ The role of NE in epilepsy was initially depicted through a kindling model, reproduced by engineered rats, in which NE seemed to delay the onset of seizure 'kindling' by the amygdala. ${ }^{63,64}$ More recent studies have revealed that NE also counteracts the development of epileptic circuits and even increases neuronal damage caused by epileptic states. ${ }^{65}$

Apart from the effects of psychotropic drugs, our study also found that higher levels of serum triglycerides correlated with higher initial ST, and higher serum LDL levels correlated with higher $\Delta \mathrm{ST}_{10 \mathrm{th}}$ values. Related ideas can be traced back to the classical ketogenic diet designed for children with intractable epilepsy. A diet of high fats and low carbohydrates is expected to be ketogenic and increase serum ketone levels. Ketosis is anticipated to activate the tricarboxylic acid cycle and increase GABA synthesis, leading to increased antiepileptic effects. ${ }^{66,67}$ Correlations between high cholesterol levels and raised ST were also observed in an animal study on epileptic monkeys. ${ }^{68}$ We did not examine serum ketone levels, which is one of the limitations of our study.

Modern drugs offer treatment choices of great efficacy to most clinicians. However, the number of treatment-resistant cases is increasing, making ECT an attractive, if not mandatory, treatment option. ${ }^{69}$ The American Psychiatric Association Task Force on ECT advises practitioners to stop concomitant use of psychotropic drugs to prevent possible adverse effects, ${ }^{70,71}$ although reviews show that most psychiatric patients ultimately end up receiving more than two psychotropic medications. ${ }^{72}$ Still, because energy levels beyond ST usually accompany more adverse effects, discontinuation of psychotropic drugs has been a customary habit for many clinicians. ${ }^{73}$ That tradition is questionable because recent reports suggest that ECT induces 5-HT receptor sensitization, possibly leading to increased drug efficacies in treatment-resistant patients. ${ }^{74}$ Future treatment-resistant cases might arise, forcing clinicians to reach out for ECT with concomitant poly-pharmacy. Previous research suggests that use of antipsychotic and antidepressant drugs can lower ST and increase seizure risks in those situa- 
tions. Our results, on the other hand, imply that modern drugs can actually raise ST, unlike most classical drugs. These findings can help predict delicate changes in ST, providing hints for safer treatment techniques with fewer side effects and more effective results.

The strength of this study is that we considered both antipsychotics and antidepressants in our search for possible effects on ST during ECT. Our research also has several limitations. First, the population size was small, and the proportion of patients taking antidepressants was smaller than that of patients taking antipsychotics. Larger populations could lead to more precise results. Second, we used equivalent dose calculations to compensate for the variety of psychotropic medications, but no universal guideline for such conversions has been published. Nevertheless, those conversions are widely used in clinical practice. Third, one of our participants was taking bupropion as an antidepressant although there are studies claiming that bupropion lowers seizure threshold. The small dose (300 mg) is less likely to make a big difference but this might have affected our results. Fourth, previous studies described about the correlations between age and seizure thresholds. Our study also showed positive correlations between age and seizure threshold shifts, but the results were not shown to be significant. We believe that a larger number of participants would have resulted in more significant outcomes.

In conclusions, this study identified factors that affect ST during ECT, specifically focusing on the effect of psychotropic drugs. We found that larger doses of antipsychotics are associated with higher initial ST, whereas antidepressants are associated with stronger shifts of ST, resulting in a steeper increase. The number and amounts of concomitantly used psychotropic drugs should always be kept in mind because titrating for ST is crucial for optimal outcomes. Higher drug doses might demand higher initial energy levels and even larger titration intervals to obtain the best treatment results. Our findings provide a basis for creating safer and more efficient ECT protocols.

\section{Acknowledgments}

This study was supported by a grant from the Korea University, Republic of Korea (K1512631).

\section{REFERENCES}

1. Bersani G, Iannitelli A, Caredda M, Bersani FS, Orsi P, Pacitti F. Seizure threshold variations in ECT-treated chronic patients with schizophrenia: a brief report. Riv Psichiatr 2014;49:84-88.

2. Galvez V, Hadzi-Pavlovic D, Smith D, Loo CK. Predictors of seizure threshold in right unilateral ultrabrief electroconvulsive therapy: role of concomitant medications and anaesthesia used. Brain Stimul 2015; 8:486-492.

3. van Waarde JA, van Oudheusden LJ, Verwey B, Giltay EJ, van der Mast RC. Clinical predictors of seizure threshold in electroconvulsive therapy: a prospective study. Eur Arch Psychiatry Clin Neurosci 2013;263:
167-175.

4. Duthie AC, Perrin JS, Bennett DM, Currie J, Reid IC. Anticonvulsant mechanisms of electroconvulsive therapy and relation to therapeutic efficacy. J ECT 2015;31:173-178.

5. Maletzky BM. Seizure duration and clinical effect in electroconvulsive therapy. Compr Psychiatry 1978;19:541-550.

6. Sackeim HA, Prudic J, Devanand DP, Kiersky JE, Fitzsimons L, Moody BJ, et al. Effects of stimulus intensity and electrode placement on the efficacy and cognitive effects of electroconvulsive therapy. N Engl J Med 1993;328:839-846.

7. Enns M, Karvelas L. Electrical dose titration for electroconvulsive therapy: a comparison with dose prediction methods. Convuls Ther 1995; 11:86-93.

8. Royal College of Psychiatrists. Special Committee on ECT (2nd) Freeman C. The ECT handbook: The Second Report of the Royal College of Psychiatrists' Special Committee on ECT. London: Royal College of Psychiatrists; 1995.

9. Abrams R. Stimulus titration and ECT dosing. J ECT 2002;18:3-9; discussion 14-15.

10. Petrides G, Braga RJ, Fink M, Mueller M, Knapp R, Husain M, et al. Seizure threshold in a large sample: implications for stimulus dosing strategies in bilateral electroconvulsive therapy: a report from CORE. J ECT 2009;25:232-237.

11. Yasuda K, Kobayashi K, Yamaguchi M, Tanaka K, Fujii T, Kitahara Y, et al. Seizure threshold and the half-age method in bilateral electroconvulsive therapy in Japanese patients. Psychiatry Clin Neurosci 2015;69: 49-54.

12. Datto C, Rai AK, Ilivicky HJ, Caroff SN. Augmentation of seizure induction in electroconvulsive therapy: a clinical reappraisal. J ECT 2002;18:118-125.

13. Deng ZD, Lisanby SH, Peterchev AV. Controlling stimulation strength and focality in electroconvulsive therapy via current amplitude and electrode size and spacing. J ECT 2013;29:325.

14. Chanpattana W, Buppanharun W, Raksakietisak S, McCall WV, Somchai Chakrabhand ML. Seizure threshold rise during electroconvulsive therapy in schizophrenic patients. Psychiatry Res 2000;96:31-40.

15. Hedges D, Jeppson K, Whitehead P. Antipsychotic medication and seizures: a review. Drugs Today (Barc) 2003;39:551-557.

16. Nitturkar AR, Sinha P, Bagewadi VI, Thirthalli J. Effect of age and anticonvulsants on seizure threshold during bilateral electroconvulsive therapy with brief-pulse stimulus: a chart-based analysis. Indian J Psychiatry 2016;58:190-197.

17. Pisani F, Oteri G, Costa C, Di Raimondo G, Di Perri R. Effects of psychotropic drugs on seizure threshold. Drug Saf 2002;25:91-110.

18. Herz MI, Liberman RP, Lieberman JA, Marder SR, McGlashan TH, Wyatt RJ, et al. Practice guideline for the treatment of patients with schizophrenia. Am J Psychiatry 1997;154:1-63.

19. Woods SW. Chlorpromazine equivalent doses for the newer atypical antipsychotics. J Clin Psychiatry 2003;64:663-667.

20. Hayasaka Y, Purgato M, Magni LR, Ogawa Y, Takeshima N, Cipriani A, et al. Dose equivalents of antidepressants: evidence-based recommendations from randomized controlled trials. J Affect Disord 2015;180: 179-184.

21. Ogren SO, Pakh B. Effects of dopamine-D(1) and dopamine-D(2) receptor agonists and antagonists on seizures induced by chemoconvulsants in mice. Pharmacol Toxicol 1993;72:213-220.

22. Okazaki M, Adachi N, Akanuma N, Hara K, Ito M, Kato M, et al. Do antipsychotic drugs increase seizure frequency in epilepsy patients? Eur Neuropsychopharmacol 2014;24:1738-1744.

23. Torta R, Monaco F. Atypical antipsychotics and serotoninergic antidepressants in patients with epilepsy: pharmacodynamic considerations. Epilepsia 2002;43(Suppl 2):8-13.

24. Devinsky O, Honigfeld G, Patin J. Clozapine-related seizures. Neurology 1991;41:369-371.

25. Pacia SV, Devinsky O. Clozapine-related seizures-experience with 5,629 
patients. Neurology 1994;44:2247-2249.

26. Taner E, Cosar B, Demir EY, Isyk E. Clozapine related seizures: prevalence and characteristic features. Int J Neuropsychopharmacology 2006;9:S277-S277.

27. Moezi L, Hosseini M, Oveisi S, Niknahad H, Shafaroodi H. The effects of sub-chronic treatment with aripiprazole on pentylenetetrazole- and electroshock-induced seizures in mice: the role of nitric oxide. Pharmacology 2015;95:264-270.

28. Burke K, Chandler CJ, Starr BS, Starr MS. Seizure Promotion and Protection by D-1 and D-2 Dopaminergic Drugs in the Mouse. Pharmacol Biochem Behav 1990;36:729-733.

29. al-Tajir G, Chandler CJ, Starr BS, Starr MS. Opposite Effects of Stimulation of D1 and D2 Dopamine-Receptors on the Expression of Motor Seizures in Mouse and Rat. Neuropharmacology 1990;29:657-661.

30. al-Tajir G, Starr MS, Starr BS. Proconvulsant Effect of Skf-38393 Mediated by Nigral D1 Receptors. Eur J Pharmacol 1990;182:245-251.

31. Starr MS, Starr BS. Seizure promotion by D(1) agonists does not correlate with other dopaminergic properties. J Neural Transm Park Dis Dement Sect 1993;6:27-34.

32. Yokoyama H, Onodera K, Iinuma K. MK-801 and dopaminergic system in electrically-induced convulsions in mice. Yakubutsu Seishin Kodo 1993;13:309-313.

33. Frey HH, Popp C, Loscher W. Influence of inhibitors of the high affinity GABA uptake on seizure thresholds in mice. Neuropharmacology 1979; 18:581-590.

34. Krogsgaard-Larsen P, Falch E, Larsson OM, Schousboe A. GABA uptake inhibitors: relevance to antiepileptic drug research. Epilepsy Res 1987;1:77-93.

35. Sanacora G, Mason GF, Rothman DL, Hyder F, Ciarcia JJ, Ostroff RB, et al. Increased cortical GABA concentrations in depressed patients receiving ECT. Am J Psychiatry 2003;160:577-579.

36. Farnbach-Pralong D, Bradbury R, Copolov D, Dean B. Clozapine and olanzapine treatment decreases rat cortical and limbic GABA(A) receptors. Eur J Pharmacol 1998;349:R7-R8.

37. Nazari-Serenjeh F, Rezayof A, Zarrindast MR. Functional correlation between gabaergic and dopaminergic systems of dorsal hippocampus and ventral tegmental area in passive avoidance learning in rats. Neuroscience 2011;196:104-114.

38. Mrzljak L, Bergson C, Pappy M, Huff R, Levenson R, GoldmanRakic PS. Localization of dopamine D4 receptors in GABAergic neurons of the primate brain. Nature 1996;381:245-248.

39. Seamans JK, Gorelova N, Durstewitz D, Yang CR. Bidirectional dopamine modulation of GABAergic inhibition in prefrontal cortical pyramidal neurons. J Neurosci 2001;21:3628-3638.

40. Floran B, Aceves J, Sierra A, Martinez-Fong D. Activation of D1 dopamine-receptors stimulates the release of gaba in the basal ganglia of the rat. Neurosci Lett 1990;116:136-140.

41. Reubi JC, Iversen LL, Jessell TM. Dopamine selectively increases H3-Gaba release from slices of rat substantia nigra invitro. Nature 1977; 268:652-654.

42. Bernath S, Zigmond MJ. Dopamine may influence striatal gaba release via 3 separate mechanisms. Brain Res 1989;476:373-376.

43. Mula M, Monaco F, Trimble MR. Use of psychotropic drugs in patients with epilepsy: interactions and seizure risk. Exp Rev Neurother 2004;4: 953-964.

44. Koch-Stoecker S. Antipsychotic drugs and epilepsy: indications and treatment guidelines. Epilepsia 2002;43(suppl 2):19-24.

45. Centorrino F, Price BH, Tuttle M, Bahk WM, Hennen J, Albert MJ, et al. EEG abnormalities during treatment with typical and atypical Antipsychotics. Am J Psychiatry 2002;159:109-115.

46. Moller HJ. Antipsychotic and antidepressive effects of second generation antipsychotics-two different pharmacological mechanisms? Eur Arch Psychiatry Clin Neurosci 2005;255:190-201.

47. Yang Y, Gao X, Xu Y. The dilemma of treatments for epileptic patients with depression. Int J Neurosci 2015;125:566-577.
48. Montgomery SA. Antidepressants and seizures: emphasis on newer agents and clinical implications. Int J Clin Pract 2005;59:1435-1440.

49. Citraro R, Leo A, De Fazio P, De Sarro G, Russo E. Antidepressants but not antipsychotics have antiepileptogenic effects with limited effects on comorbid depressive-like behaviour in the WAG/Rij rat model of absence epilepsy. Br J Pharmacol 2015;172:3177-3188.

50. Lloyd KG, Pichat P. GABA synapses, depression, and antidepressant drugs. Psychopharmacol Ser 1987;3:113-126.

51. Shiah IS, Yatham LN. GABA function in mood disorders: an update and critical review. Life Sci 1998;63:1289-1303.

52. Ropert N, Guy N. Serotonin facilitates GABAergic transmission in the CA1 region of rat hippocampus in vitro. J Physiol 1991;441:121-136.

53. McCormick DA, Wang Z. Serotonin and noradrenaline excite GABAergic neurones of the guinea-pig and cat nucleus reticularis thalami. J Physiol 1991;442:235-255.

54. Ciranna L. Serotonin as a modulator of glutamate- and GABA-mediated neurotransmission: implications in physiological functions and in pathology. Curr Neuropharmacol 2006;4:101-114.

55. Filakovszky J, Gerber K, Bagdy G. A serotonin-1A receptor agonist and an N-methyl-D-aspartate receptor antagonist oppose each others effects in a genetic rat epilepsy model. Neurosci Lett 1999;261:89-92.

56. Bagdy G, Kecskemeti V, Riba P, Jakus R. Serotonin and epilepsy. J Neurochem 2007;100:857-873.

57. Bhagwagar Z, Wylezinska M, Taylor M, Jezzard P, Matthews PM, Cowen PJ. Increased brain GABA concentrations following acute administration of a selective serotonin reuptake inhibitor. Am J Psychiatry 2004; 161:368-370.

58. Bowers G, Cullinan WE, Herman JP. Region-specific regulation of glutamic acid decarboxylase (GAD) mRNA expression in central stress circuits. J Neurosci 1998;18:5938-5947.

59. Herman JP, Renda A, Bodie B. Norepinephrine-gamma-aminobutyric acid (GABA) interaction in limbic stress circuits: effects of reboxetine on GABAergic neurons. Biol Psychiatry 2003;53:166-174.

60. Beverly JL, de Vries MG, Beverly MF, Arseneau LM. Norepinephrine mediates glucoprivic-induced increase in GABA in the ventromedial hypothalamus of rats. Am J Physiol Regul Integr Comp Physiol 2000; 279:R990-R996.

61. Segal M, Bloom FE. The action of norepinephrine in the rat hippocampus. II. Activation of the input pathway. Brain Res 1974;72:99-114.

62. Szot P, Weinshenker D, White SS, Robbins CA, Rust NC, Schwartzkroin PA, et al. Norepinephrine-deficient mice have increased susceptibility to seizure-inducing stimuli. J Neurosci 1999;19:10985-10992.

63. Dailey JW, Jobe PC. Indices of noradrenergic function in the central nervous system of seizure-naive genetically epilepsy-prone rats. Epilepsia 1986;27:665-670.

64. Browning RA, Wade DR, Marcinczyk M, Long GL, Jobe PC. Regional brain abnormalities in norepinephrine uptake and dopamine beta-hydroxylase activity in the genetically epilepsy-prone rat. J Pharmacol Exp Ther 1989;249:229-235.

65. Giorgi FS, Pizzanelli C, Biagioni F, Murri L, Fornai F. The role of norepinephrine in epilepsy: from the bench to the bedside. Neurosci Biobehav Rev 2004;28:507-524.

66. Bough KJ, Rho JM. Anticonvulsant mechanisms of the ketogenic diet. Epilepsia 2007;48:43-58.

67. Leke R, Bak LK, Iversen P, Sorensen M, Keiding S, Vilstrup H, et al. Synthesis of neurotransmitter GABA via the neuronal tricarboxylic acid cycle is elevated in rats with liver cirrhosis consistent with a high GABAergic tone in chronic hepatic encephalopathy. J Neurochem 2011;117: 824-832.

68. Kopeloff LM, Alexander GJ. Serum cholesterol in monkeys with chronic epileptic foci. Life Sci I 1971;10:869-876.

69. McClintock SM, Choi J, Deng ZD, Appelbaum LG, Krystal AD, Lisanby $\mathrm{SH}$. Multifactorial determinants of the neurocognitive effects of electroconvulsive therapy. J ECT 2014;30:165-176.

70. Haskett RF, Loo C. Adjunctive psychotropic medications during elec- 
troconvulsive therapy in the treatment of depression, mania, and schizophrenia. J ECT 2010;26:196-201.

71. Sackeim HA, Dillingham EM, Prudic J, Cooper T, McCall WV, Rosenquist $\mathrm{P}$, et al. Effect of concomitant pharmacotherapy on electroconvulsive therapy outcomes: short-term efficacy and adverse effects. Arch Gen Psychiatry 2009;66:729-737.

72. Kristensen D, Hageman I, Bauer J, Jorgensen MB, Correll CU. Antipsychotic polypharmacy in a treatment-refractory schizophrenia popula- tion receiving adjunctive treatment with electroconvulsive therapy. J ECT 2013;29:271-276.

73. Fink M, Kellner CH. ECT and drugs: concurrent Administration. Convuls Ther 1993;9:237-240.

74. Ishihara K, Sasa M. Mechanism underlying the therapeutic effects of electroconvulsive therapy (ECT) on depression. Jpn J Pharmacol 1999; 80:185-189. 